\title{
EXTENDED KALMAN FILTER DESIGN FOR RAILWAY TRACTION MOTOR
}

\author{
${ }^{1}$ Caglar UYULAN, ${ }^{2}$ Metin GOKASAN \\ ${ }^{1}$ Istanbul Technical University, Department of Mechatronics Engineering, Graduate School of Science, \\ Engineering and Technology, Istanbul, TURKEY \\ ${ }^{2}$ Istanbul Technical University, Department of Control Engineering, Faculty of Electrical and Electronic \\ Engineering, Istanbul, TURKEY \\ 1'cuyulan@itu.edu.tr, 2gokasan@itu.edu.tr
}

(Geliş/Received: 06.02.2017; Kabul/Accepted in Revised Form: 14.04.2017)

\begin{abstract}
Monitoring the adhesion force between a railway wheel and a rail surface is very essential in maintaining high acceleration and braking performance of railway vehicles. Due to the difficulties encountered in direct measurement of friction coefficient, creepage and adhesion force; state observers are used as indirect estimation methods. This paper proposes an effective estimation method, which exploits railway traction motor behaviour to give an assistance for realizing wheel slip and adhesion control in order to be used in railway applications. This method plays an active role in optimizing the use of the existing adhesion and reducing wheel wear by decreasing high creep values. With this method, adhesion force can be indirectly estimated by measuring stator currents, and angular speed of the AC traction motor and using dynamic relationships based on the extended Kalman filter (EKF) simulation model. The re-adhesion controller can be designed to regulate the motor torque command according to the maximum available adhesion depending on the estimated results. To test the proposed method, simulations were performed under different friction coefficients.
\end{abstract}

Key Words: Adhesion mode, Extended Kalman filter, Full state estimation, Railway traction.

\section{Demiryolu Cer Motorları için Genişletilmiş Kalman Filtresi Tasarımı}

ÖZ: Bir demiryolu tekerleği ile rayı arasında meydana gelen tutunma kuvvetinin izlenmesi, demiryolu araçlarının yüksek hızlanma ve frenleme performansının korunmasında oldukça önemlidir. Sürtünme katsayısı, kayma ve tutunma kuvvetinin doğrudan ölçülmesinde karşılaşılan zorluklardan dolayı, durum gözetleyicilerine dayalı dolaylı tahmin yöntemleri kullanılır. Bu makale, demiryolu uygulamalarında kullanılmak üzere tekerlek kayma ve yeniden tutunma kontrolünü gerçekleştirmek için demiryolu cer motor davranışını kullanan etkili bir tahmin yöntemi önermektedir. Bu yöntem, mevcut tutunmanın kullanımını iyileştirmede ve yüksek kayma değerlerini düşürerek tekerlek aşınmasının azaltılmasında etkin bir rol oynamaktadır. Bu yöntemle, stator akımları ve asenkron cer motorun açısal hızı ölçülerek, genişletilmiş Kalman filtresi (GKF) simülasyon modeline dayanan dinamik ilişkiler kullanılarak tutunma kuvveti dolaylı olarak tahmin edilebilir. Yeniden tutunma kontrolörü, tahmin sonuçlarına bağlı olan maksimum erişilebilir tutunma özelliklerine göre motor moment komutu düzenlenerek tasarlanabilir. Önerilen yöntemi test etmek için, farklı tekerlek-ray sürtünme katsayıları altında simülasyonlar gerçekleştirilmiştir.

Anahtar Kelimeler: Demiryolu Cer sistemi, Genişletilmiş Kalman filtresi, Tam durum kestirimi, Tutunma modeli. 


\section{INTRODUCTION}

In railway vehicles, estimating the maximum adhesion force between the wheel and rail, which is a non-linear function of friction coefficient and mass of the rail vehicle, is very important in terms of providing effective acceleration and braking performance. In traction systems, excessive creepage at the wheel-rail must be limited to reduce traction, poor ride comfort, wheel wear and noise. A large creepage usually occurs when the traction force applied during acceleration and deceleration exceeds the maximum admissible adhesion. When investigating the slip\&slide phenomenon in railway traction, a procedure based on the second order Luenberger observer that indirectly define the frictional force is proposed and the results obtained are verified on the test rig (Rizzo and Iannuzzi, 2002). The load is evaluated by means of the interaction between the torsional oscillations of the friction forces, mechanical transmission forces, and the motion components to optimize the vector control algorithm, which prevents slip\&slide oscillations. An adaptive observer algorithm has been developed to approximate the true wheel-rail friction coefficient by using the measured values of the angular velocity of the wheel, the moment generated by the brake force and the torque generated by the wheel load. Friction coefficient values estimated under suddenly changing wheel-rail contact conditions are used to improve anti-slip brake control performance (Gaspar et al., 2006). However, in this method, it is necessary to know the slip ratio and vehicle speed so that the friction coefficient can be estimated. This method does not seem to have enough accuracy because of the difficulty of measuring slip ratio and vehicle speed. Lateral dynamics of the train have also been analyzed to estimate the low adhesion at the wheel-rail contact by using Kalman filter algorithm (Charles and Goodall, 2006). The shortcoming of this method is that it only detects significant changes in friction coefficient. Subsequent studies have involved searching for the least residuals operated at saturation points under the influence of different friction coefficients, using the series of state observers in the estimation of the vehicle lateral dynamics and friction coefficients (Mei and Hussain, 2010). The creep force between the wheel and roller is estimated using Kalman filter based on stator voltage, current and motor speed measurement focusing on the torsional dynamics of a simplified drive system. The estimated creep force-creepage relationship is compared with those under different friction coefficients, and the friction coefficient is estimated by calculating the root mean square value of residuals (Zhao et al., 2012). A multiple-induction motor system driven by a single inverter, which utilize the estimated adhesion force to adjust the torque command and suppress the slip\&slide, has been investigated. The ability of the traction system to be adjusted to work at the peak of the adhesion force curve depends on accurately estimating the friction coefficient and vehicle speed (Kawamura et al., 2003; Matsumoto et al., 2001). The creep forces occurred at the contact patch have been investigated by using the roller test rig and a model to calculate the wheel-rail creep force has been proposed (Iwnicki, 2003). Among the alternative methods, there is an indirectly detection and estimation process of the slip-slide conditions based on measuring the voltage, current, and speed of the AC traction motor with using an EKF (Zhao and Liang, 2013). There is also another method were used to detect slip velocity based on the multi-rate EKF state identification by combining the multi-rate method and the EKF method to identify traction motor load torque. This method provides a faster detection of slip and improves reliability and traction performance (Wang et al., 2016). The EKF algorithm has been developed for direct vector control of induction motors. This algorithm includes the estimation of the currents, rotor fluxes, and motor speed (Barut et al., 2002). In the sixth-order discrete-time model, mechanical equations are taken into consideration by adding the load torque to the state variables (Alonge and D'ippolito, 2010). The important problem associated with the use of EKF's is the proper selection of covariance matrices and measurement noises for the system to operate at the optimal state. However, both matrices are not known, especially the system noise is very hard to define. For this reason, these matrices are often used as parameters for tuning. Adjustment can be accomplished using a trial and error approach or using evolutionary algorithms (Cai, et al., 2003). A Kalman-Bucy filter estimation method based on a half vehicle non-linear contact mechanics model was developed in (Ward et al., 2011) and best estimates were achieved for the front bogie rear wheelset creep forces. The 
efficiency of this technique was tested with more representative data produced by multi-bodied physics simulation package Vampire (Ward et al., 2012). Multiple model estimation approach for the identification of the adhesion limit to handle the wheel slip/slide phenomenon was presented by using a bank of Kalman filters, which are designed at selected operation points for adhesion estimation (Hussain et al., 2013)

An unscented Kalman filter was also used to estimate the creep force, creepage and the friction coefficient from traction motor behaviors (Zhao, et al., 2014). This estimator provided accurate friction estimation under different contact conditions, but the estimated friction coefficient was not reliable when the traction load is very small, and was also influenced by the traction load. These problems are originated from the inaccuracy of the measurements and system dynamic model. An adhesion moment estimation in contact point was constructed in order to perform a high precision adaptive control system for locomotive electrical drives (Radionov and Mushenko, 2015). By using this method, it is also possible to estimate the rotor flux vector components.

In this paper, a new approach to estimate the adhesion force between wheel-rail contact surfaces over an EKF using the measured values of the stator currents of the traction AC motor has been examined. The optimum operating point of the system is determined by the estimated adhesion forcecreepage curve. To test the observer, a dynamic model consisting of a wheel set, gear box and traction motor is designed. The Polach model is used to express the wheel-rail contact behavior. For sensorless control of induction motors, an EKF is proposed that estimates rotor flux and current components, motor speed and load torque. The traction motor is designed by first order decomposition of the sixth order nonlinear model (Euler method). The mechanical equation is formed by including the load torque in the state variables that the account participates in. Then, based on this model, the EKF design was completed by selecting the covariance matrices of the system and the measurement noise using a trial and error method. The main contribution of this paper is to design and implement the sixth-order EKF, which takes into account the railway traction dynamics and predicts the existing adhesion to establish an effective sensorless re-adhesion control system on rail vehicles.

\section{MATERIAL AND METHOD}

\section{Traction system model}

The traction system used in this paper is represented in Figure 1.

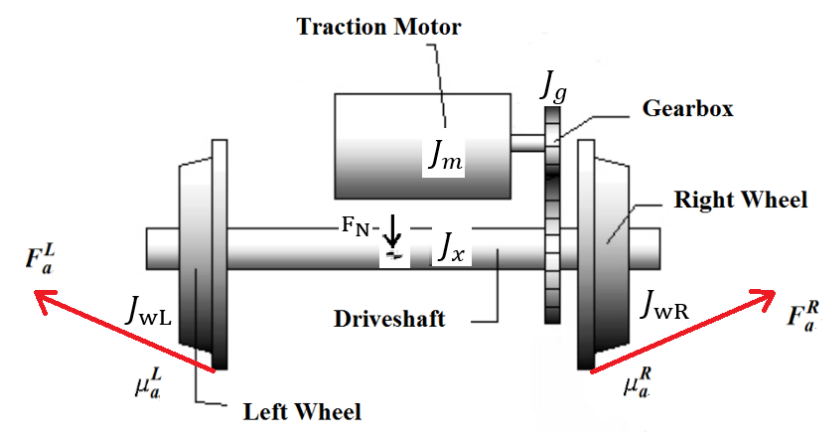

Figure 1. Schematic representation of the traction system.

In this system, a wheel set with two wheels is driven by an AC induction motor coupled with a gearbox. The movement of the railway vehicle takes place thanks to the creep forces between the wheels and the rail. The dynamic equations for the motion of the system are given below.

$$
\frac{\mathrm{d} \omega_{m}}{\mathrm{~d} t}=\frac{T_{m}-T_{L}}{J_{\mathrm{eqv}}}
$$




$$
\omega_{w}=\frac{\omega_{m}}{n_{i}}
$$

where $\omega_{m}$ is the motor angular velocity, $\omega_{w}$ is the wheel angular velocity, $T_{m}$ is the motor torque, $n_{i}$ is the gear reduction ratio, $T_{L}$ is the load torque and represented as $T_{L}=\frac{2 r_{0} F_{a}}{n_{i}}$, here $F_{a}$ is the longitudinal creep force, which is also called as adhesion force of a single wheel.

$J_{\text {eqv }}$ is the equivalent moment of inertia as shown in below

$$
J_{\mathrm{eqv}}=J_{m}+\frac{J_{g}+J_{x}+J_{\mathrm{wR}}+J_{\mathrm{wL}}}{n_{i}^{2}}
$$

where $J_{g}, J_{x}, J_{\mathrm{wR}}, J_{\mathrm{wL}}$ is the moment of inertia of the gearbox, wheelset axle, right wheel, left wheel, respectively.

\section{Extended mathematical model of the traction motor}

In this paper, the type of the traction motor is an induction motor, which is controlled by an indirect flux oriented scheme, which is commonly used in railway traction. Induction motors are described by a set of fifth-order differential equations with two input and three state variables suitable for measurement. The model for speed sensorless control includes differential equations based on stator and/or rotor electric circuits, taking into account stator current and/or voltage measurement. The extended induction motor model derived is different from previous EKF-based estimators that estimate the rotor speed. The equation of motion to be used for estimating the rotor speed is also included in the model. Stator current and rotor flux are the state variables and the equations are listed as (Barut, et al., 2007; Shi et al., 2002 )

$$
\begin{aligned}
& \frac{\mathrm{d} I_{s \alpha}}{\mathrm{d} t}=-\left(\frac{R_{s}}{\sigma L_{s}}+\frac{L_{m}^{2} R_{r}^{\prime}}{\sigma L_{s}\left(L_{r}^{\prime}\right)^{2}}\right) I_{s \alpha}+\frac{L_{m} R_{r}^{\prime}}{\sigma L_{s}\left(L_{r}^{\prime}\right)^{2}} \psi_{r \alpha}+\frac{L_{m}}{\sigma L_{s} L_{r}^{\prime}} n_{p} \omega_{m} \psi_{r \beta}+\frac{1}{\sigma L_{s}} U_{s \alpha} \\
& \frac{\mathrm{d} I_{s \beta}}{\mathrm{d} t}=-\left(\frac{R_{s}}{\sigma L_{s}}+\frac{L_{m}^{2} R_{r}^{\prime}}{\sigma L_{s}\left(L_{r}^{\prime}\right)^{2}}\right) I_{s \beta}+\frac{L_{m} R_{r}^{\prime}}{\sigma L_{s}\left(L_{r}^{\prime}\right)^{2}} \psi_{r \beta}-\frac{L_{m}}{\sigma L_{s} L_{r}^{\prime}} n_{p} \omega_{m} \psi_{r \alpha}+\frac{1}{\sigma L_{s}} U_{s \beta} \\
& \frac{\mathrm{d} \psi_{r \alpha}}{\mathrm{d} t}=\frac{R_{r}^{\prime} L_{m}}{L_{r}^{\prime}} I_{s \alpha}-\frac{R_{r}^{\prime}}{L_{r}^{\prime}} \psi_{r \alpha}-n_{p} \omega_{m} \psi_{r \beta} \\
& \frac{\mathrm{d} \psi_{r \beta}}{\mathrm{d} t}=\frac{R_{r}^{\prime} L_{m}}{L_{r}^{\prime}} I_{s \beta}-\frac{R_{r}^{\prime}}{L_{r}^{\prime}} \psi_{r \beta}+n_{p} \omega_{m} \psi_{r \alpha} \\
& \frac{\mathrm{d} \omega_{m}}{\mathrm{~d} t}=\frac{-3 n_{p} L_{m}}{2 J_{e q v} L_{r}^{\prime}} \psi_{r \beta} I_{s \alpha}+\frac{3 n_{p} L_{m}}{2 J_{e q v} L_{r}^{\prime}} \psi_{r \alpha} I_{s \beta}-\frac{B_{m}}{J_{e q v}} \omega_{m}-\frac{\mathrm{T}_{L}}{J_{e q v}}
\end{aligned}
$$

The extended model of the induction motor based on the rotor flux is represented in matrix form as (Barut et al., 2005)

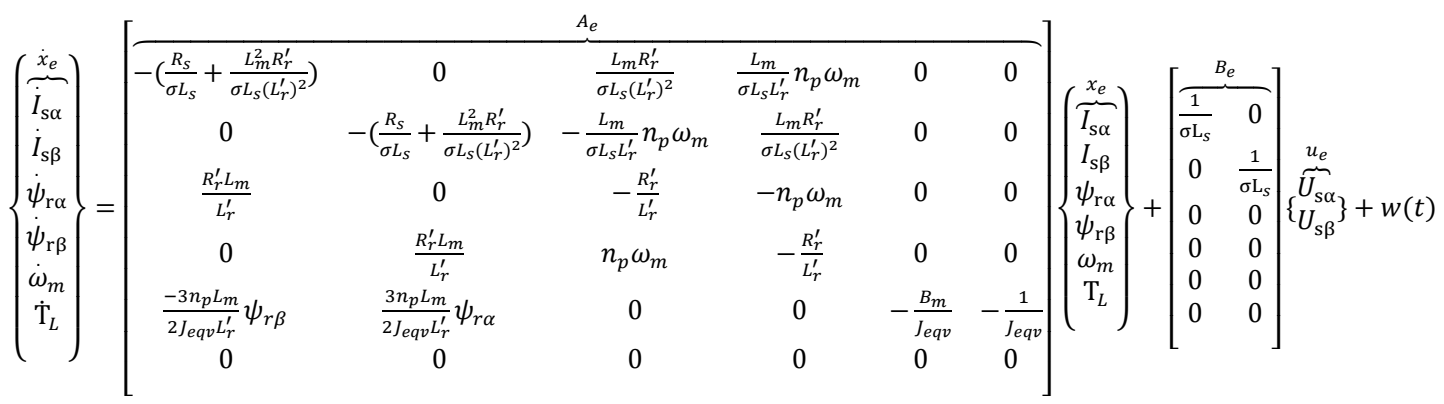




$$
\left[\begin{array}{c}
\overbrace{I_{s \alpha}}^{\mathrm{z}} \\
I_{\mathrm{s} \beta} \\
\omega_{m}
\end{array}\right]=[\overbrace{100000}^{H_{e}}]\left[\begin{array}{c}
I_{\mathrm{s} \alpha} \\
I_{\mathrm{s} \beta} \\
\psi_{\mathrm{r} \alpha} \\
\psi_{\mathrm{r} \beta} \\
\omega_{m} \\
F_{a}
\end{array}\right\}+v(t)
$$

where $n_{p}$ is the number of the pole pairs, $\sigma$ is the leakage or coupling factor, $L_{s}$ and $R_{s}$ are stator inductance and resistance, respectively, $L_{r}^{\prime}$ and $R_{r}^{\prime}$ is the rotor inductance and resistance, referred to the stator side, respectively. $U_{s \alpha}$ and $U_{s \beta}$ stator stationary axis components of stator voltages, $\psi_{r \alpha}$ and $\psi_{r \beta}$ are rotor stationary axis components of stator flux, $L_{m}$ is the mutual inductance, $B_{m}$ is the viscous friction, $w(t)$ and $v(t)$ are process and measurement noise, respectively.

The longitudinal creep force $F_{a}$ at the wheel-rail contact is modeled based on Polach's method as (Polach, 1999)

$$
F_{a}=\frac{2 \mathrm{~F}_{\mathrm{N}} \mu_{\mathrm{f}}}{\pi}\left(\frac{\mathrm{k}_{\mathrm{A}} \epsilon}{1+\left(\mathrm{k}_{\mathrm{A}} \epsilon\right)^{2}}+\arctan \left(\mathrm{k}_{\mathrm{S}} \epsilon\right)\right)
$$

For the case of the domination of the "longitudinal creepage" $\quad \xi_{\mathrm{x}} \approx \xi, \xi_{\mathrm{y}} \approx 0$ "

$$
\epsilon=\frac{G \pi a b C_{11}}{4 F_{N} \mu_{\mathrm{f}}} \xi
$$

where $a, b$ are the semi-axes of the contact ellipse, $\mathrm{C}_{11}$ ise the longitudinal Kalker's coefficients, $\mathrm{F}_{\mathrm{N}}$ is the normal force acting on the wheel. $\mathrm{k}_{\mathrm{A}}, \mathrm{k}_{\mathrm{S}}$ are reduction factors regarding to the different conditions between wheel and rail surface. $\mathrm{k}_{\mathrm{A}}$ is related to the area of the adhesion, $\mathrm{k}_{\mathrm{S}}$ is related to the area of slip, and the condition is defined as

$$
\mathrm{k}_{\mathrm{S}} \leqslant \mathrm{k}_{\mathrm{A}} \leq 1
$$

In this model, the traction coefficient relies on the slip velocity and friction coefficient, which is defined by the following equation.

$$
\mu_{f}=\mu_{0}\left((1-Q) e^{-\mathrm{P} \xi \mathrm{V}}+Q\right)
$$

$P, Q$ are reduction factors under different friction coefficient. The values of the $P, Q, \mathrm{k}_{\mathrm{A}}, \mathrm{k}_{\mathrm{S}}, \mu_{0}$ are given in Table 1.

Table 1. Parameters of Polach model under various friction conditions (Zhao and Liang, 2013).

\begin{tabular}{|c|cccc|}
\hline Parameter & Dry & Wet & Low & Very Low \\
\hline $\boldsymbol{k}_{\boldsymbol{A}}$ & 1 & 1 & 1 & 1 \\
$\boldsymbol{k}_{\boldsymbol{S}}$ & 0,4 & 0,4 & 0,4 & 0,4 \\
$\boldsymbol{\mu}_{\mathbf{0}}$ & 0,55 & 0,3 & 0,06 & 0,03 \\
$\mathbf{P}$ & 0,4 & 0,4 & 0,4 & 0,4 \\
$\mathbf{Q}$ & 0,6 & 0,2 & 0,2 & 0,1 \\
\hline
\end{tabular}

Since the lateral dynamics of the system are neglected in this work, the creepage terms contain only the longitudinal component. Creepage is calculated by the following equation (Kalker, 1968). 


$$
\xi=\frac{\omega_{w} r_{0}-V}{V}
$$

where $V$ is the longitudinal velocity of the railway vehicle.

\section{Extended Kalman filter design}

An EKF algorithm with the aim of estimating the states of the extended induction motor model given in Equations (8-9), which will be used in the sensorless control of the induction motor, has been developed. The Kalman filter (KF) method used for this purpose is a recursive algorithm in which a statistical state space model is added to the system together with the measured outputs to optimally estimate states in multiple input \& multiple output systems. System and measurement noises are considered as white noise and the optimality of the state estimation can be obtained by minimizing of the covariance of the estimation error. Since KF cannot express an optimal filter performance for nonlinear problems, this difficulty is solved by the EKF method, which implements a linearization approach on the current state estimation. This method demands the discretization of the extended induction motor model (Alsofyani et al., 2012; Barut et al., 2003).

$$
\begin{aligned}
& \hat{x}_{e}^{-}(k+1)=A_{e} \hat{x}_{e}^{-}(k)+w(k)=\hat{f}_{e}\left(x_{e}(k), u_{e}(k)\right)+w(k) \\
& z(k)=\mathrm{Hx}_{e}(k)+v(k)
\end{aligned}
$$

where $A_{e}$ is the state matrix, $H$ is the measurement matrix, $w(k)$, and $v(k)$ are process and measurement noise, respectively, $z$ is the measurement vector.

The state and measurement vectors are defined as

$$
\begin{gathered}
x_{e}=\left[\begin{array}{llllll}
I_{\mathrm{s} \alpha} & I_{\mathrm{s} \beta} & \psi_{\mathrm{r} \alpha} & \psi_{\mathrm{r} \beta} & \omega_{m} & \mathrm{~T}_{L} \mathrm{l}
\end{array}\right]^{T} \\
\mathrm{z}=\left[\begin{array}{lllll}
I_{\mathrm{s} \alpha} & I_{\mathrm{s} \beta} & \omega_{m}
\end{array}\right]^{T}
\end{gathered}
$$

EKF estimates the state variables by using model inputs and measurements. EKF method has the same "prediction-correction" algorithm as the Kalman filter, but linearizes the state and observation matrix at every step of estimation and correction by evaluating the Jacobian matrices and their partial derivatives (Singh and Singh, 2013). The procedure of the EKF algorithm is depicted in Figure 2.

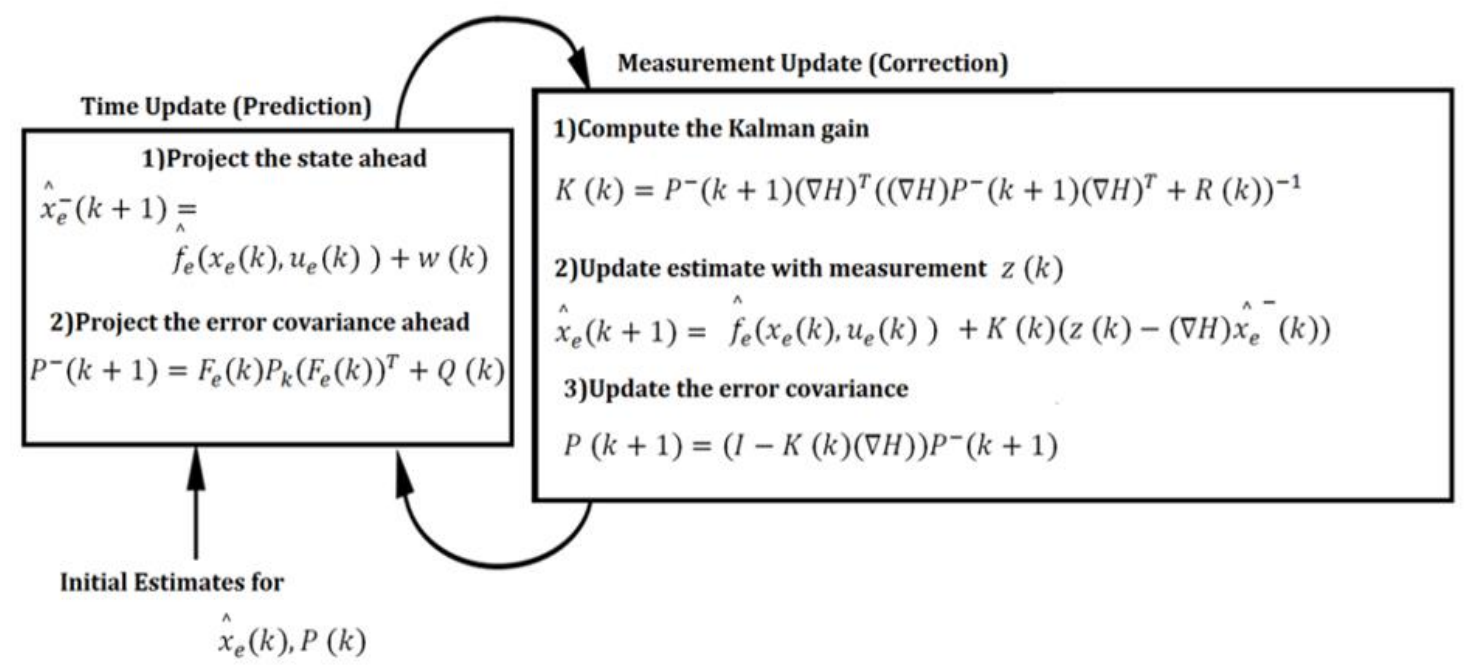

Figure 2. EKF algorithm.

The linearized approximation of the nonlinear model can be implemented by using the current estimation of the states and inputs as 


$$
\begin{aligned}
& F_{e}(k)=\left.\frac{\partial f_{e}\left(x_{e}(k), u_{e}(k)\right)}{\partial x_{e}(k)}\right|_{\hat{x}_{e}(k), \hat{u}_{e}(k)} \\
& F_{u}(k)=\left.\frac{\partial f_{e}\left(x_{e}(k), u_{e}(k)\right)}{\partial u_{e}(k)}\right|_{\hat{x}_{e}(k), \hat{u}_{e}(k)}
\end{aligned}
$$

The EKF algorithm can be defined in a recursive form as

$$
\begin{aligned}
& P^{-}(k+1)=F_{e}(k) P_{k}(k)\left(F_{e}(k)\right)^{T}+F_{u}(k) D_{u}(k)\left(F_{u}(k)\right)^{T}+Q(k) \\
& \mathrm{K}(\mathrm{k})=P^{-}(k+1) H^{T}\left(H P^{-}(k+1) H^{T}+R(k)\right)^{-1} \\
& \hat{x}_{e}(k+1)=\hat{f}_{e}\left(x_{e}(k), \hat{u}_{e}(k)\right)+\mathrm{K}(\mathrm{k})\left(z(k)-H \hat{x}_{e}(k)\right) \\
& P(k+1)=(\mathrm{I}-\mathrm{K}(\mathrm{k}) H) P^{-}(k+1)
\end{aligned}
$$

where I is the symbol of unit matrix.

The values of the covariance matrix of the system noise $Q$ and output noise $R$, can have a very large impact on the performance of the EKF. Both of these matrices should be determined by focusing the stochastic properties of the corresponding noises. Since the system and measurement noise $Q$ and $R$ have uncertainty, the their valus can be usually obtained by using the trial-and-error process (Bogosyan et al., 2007).

$\mathrm{Q}$ and $\mathrm{R}$ can be given for this simulation as:

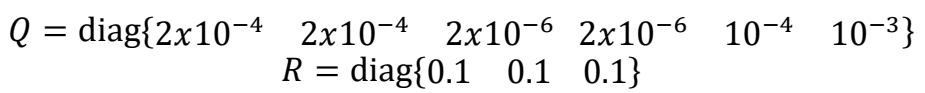

State variables $\hat{\psi}_{\mathrm{r} \alpha}, \hat{\psi}_{\mathrm{r} \beta}$, are hence $\hat{T}_{m}$ are estimated from the EKF as:

$$
\hat{T}_{m}=\frac{n_{p} L_{m}}{L_{r}^{\prime}}\left(I_{\mathrm{s} \beta} \hat{\psi}_{\mathrm{r} \alpha}-I_{\mathrm{s} \alpha} \hat{\psi}_{\mathrm{r} \beta}\right)
$$

The electric torque, which has a remarkable error during the transition of the speed command, shares the same pattern as the adhesion force $\left(\hat{F}_{a}\right)$.

\section{RESULT AND DISCUSSION}

The presented model is simulated to validate the accuracy. Parameters of the traction system used in the simulation are listed in Table 2.

Table 2. Rated values and parameters of the traction system.

\begin{tabular}{|ccccccc|}
\hline $\boldsymbol{P}_{\boldsymbol{N}}(\mathbf{k W})$ & $\boldsymbol{f}_{\mathbf{s N}}(\mathbf{H z})$ & $\boldsymbol{N}_{\boldsymbol{m}}(\mathbf{r p m})$ & $\boldsymbol{U}_{\mathbf{s N}}(\boldsymbol{V})$ & $\boldsymbol{R}_{\boldsymbol{s}}(\boldsymbol{\Omega})$ & $\boldsymbol{L}_{\boldsymbol{r}}^{\prime}(\boldsymbol{H})$ & $\boldsymbol{r}_{\mathbf{0}}(\boldsymbol{m})$ \\
\hline 250 & 50 & 2900 & 750 & 0,2890 & $2,39.10^{-3}$ & 0,34 \\
\hline $\boldsymbol{J}_{\text {eqv }}\left(\mathbf{k g} \cdot \boldsymbol{m}^{\mathbf{2}}\right)$ & $\boldsymbol{B}_{\boldsymbol{m}}\left(\frac{\boldsymbol{N} \cdot \boldsymbol{m}}{\mathbf{r a d} \cdot \boldsymbol{s}}\right)$ & $\boldsymbol{n}_{\boldsymbol{p}}$ & $\boldsymbol{R}_{\boldsymbol{r}}^{\prime}(\boldsymbol{\Omega})$ & $\boldsymbol{L}_{\boldsymbol{s}}(\boldsymbol{H})$ & $\boldsymbol{L}_{\boldsymbol{m}}(\boldsymbol{H})$ & $\boldsymbol{n}_{\boldsymbol{i}}$ \\
\hline 0,2463 & 0,0023 & 2 & 0,217 & $1,9.10^{-3}$ & $1,95.10^{-3}$ & 6,92 \\
\hline
\end{tabular}


The contact ellipse semi-axes, longitudinal Kalker's coefficient, normal force at the wheel-rail contact, shear modulus are calculated as $a=1.5 \times 10^{-3} \mathrm{~m}, b=7.5 \times 10^{-3} \mathrm{~m}, C_{11}=4.12, F_{N}=50 \mathrm{kN}$, $G=8.4 \times 10^{10} \frac{\mathrm{N}}{\mathrm{m}^{2}}$. The creep curves with respect to the various wheel-rail contact conditions are depicted in Figure 3 and the optimum creepages $\xi^{*}$, which corresponds to maximum adhesion forces.

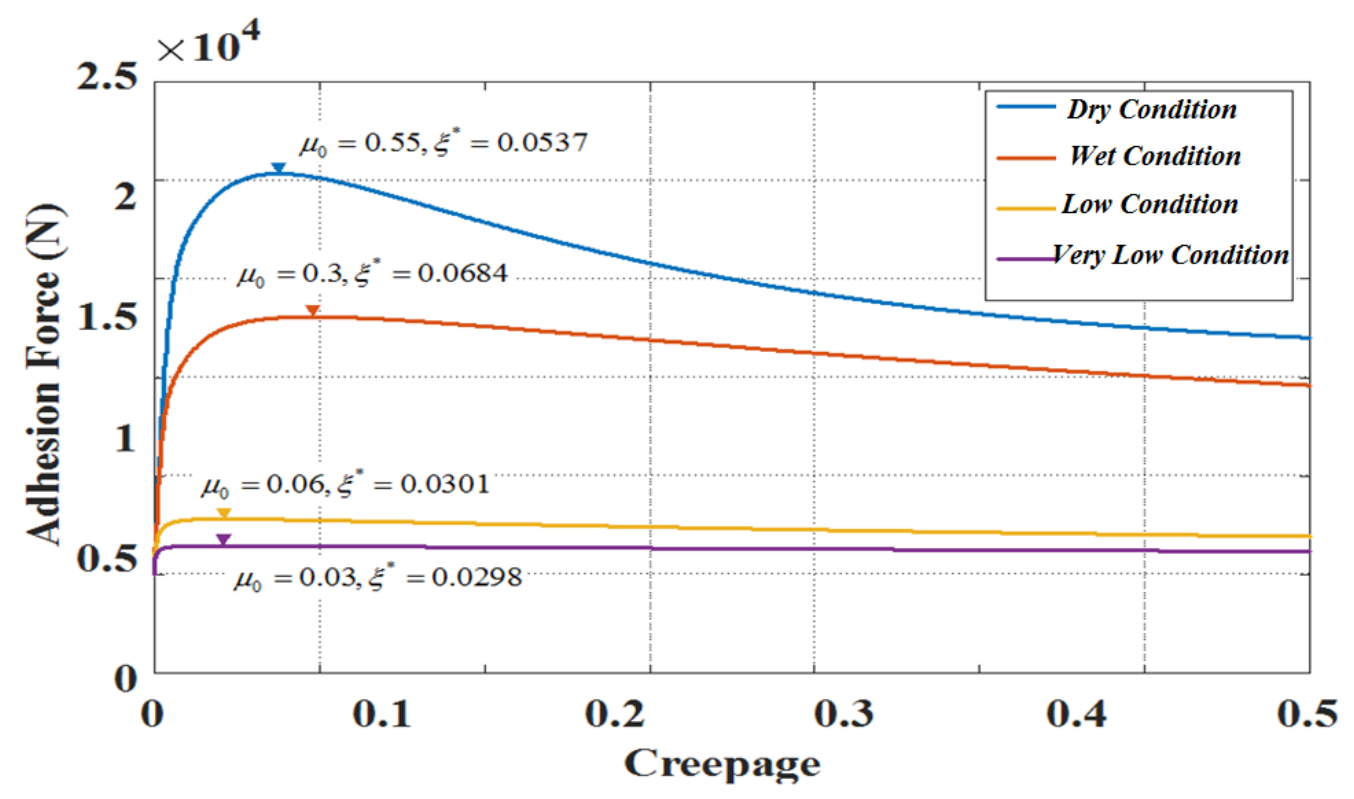

Figure 3. Creepage-adhesion force curves with different contact conditions.

The pattern of the reference motor speed $\left(\omega_{m}^{r e f}\right)$ is represented in Figure 4.

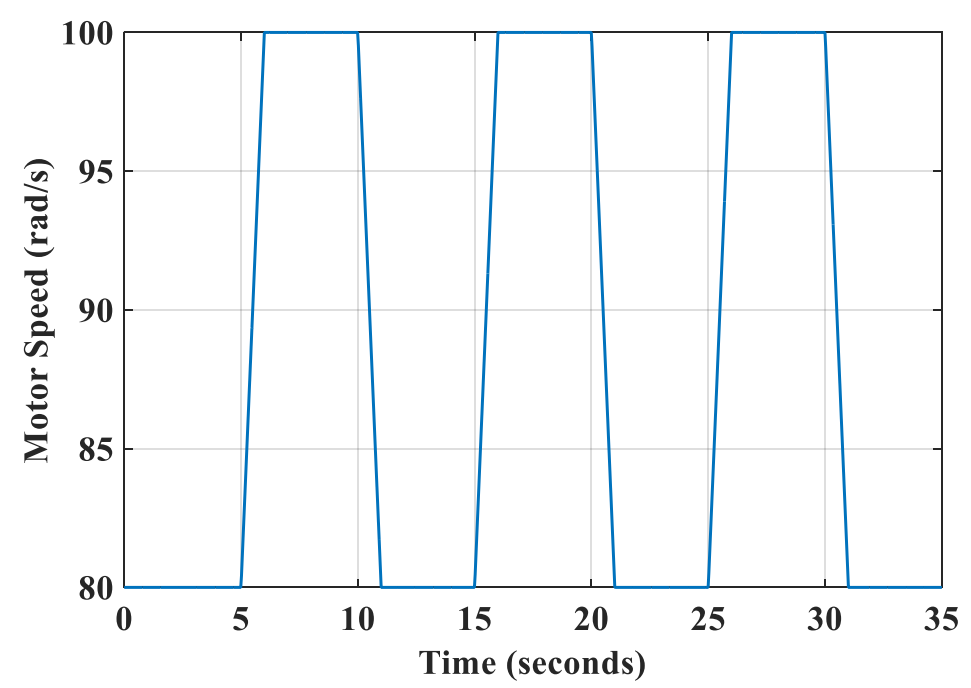

Figure 4. Reference motor speed.

The friction coefficients are designed according to the following equation to simulate dry, wet, low and very low contact conditions between the wheel and the rail.

$$
\mu_{0}=\left\{\begin{array}{cccc}
0.55 & t<10 & 0.06 & 20 \leqslant t<30 \\
0.3 & 10 \leqslant t<20 & 0.03 & 30 \leqslant t \leqslant 35
\end{array}\right.
$$

The trajectory of the estimated, actual motor speed $\left(\omega_{m}, \widehat{\omega}_{m}\right)$ and speed error $\left(e_{\omega_{m}}\right)$ were given in Figure 5, respectively. 


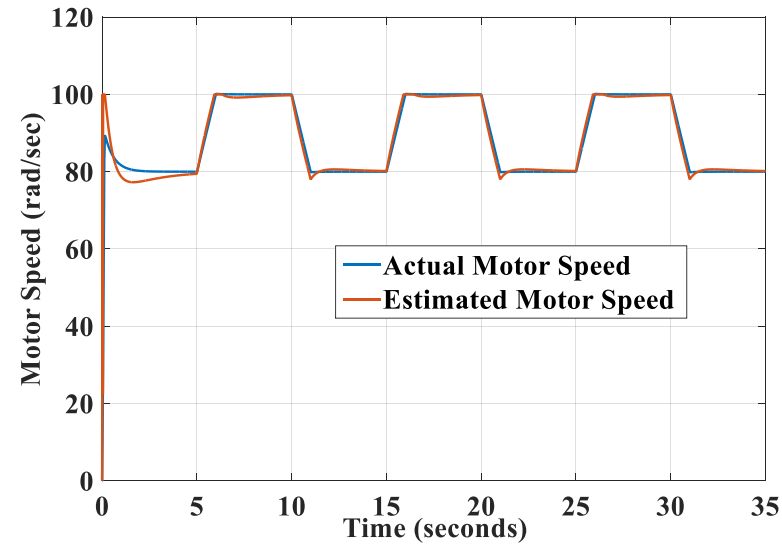

(a)

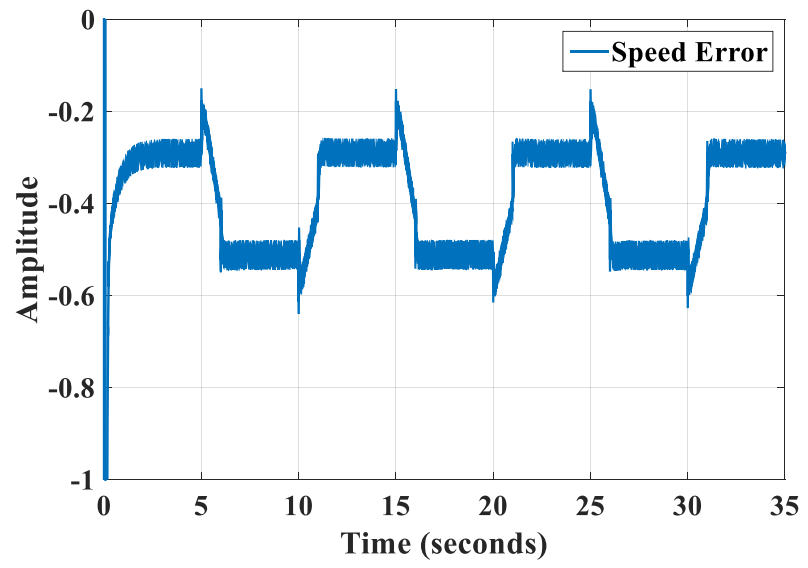

(b)

Figure 5. a)Trajectory of the estimated and actual motor speed b)The trajectory of the speed error.

It has been shown that the estimator tracks the speed trajectory with a lower bound of error and converges fast. In Figure 6, the trajectory of the estimated load torque and load torque error $\left(\widehat{T}_{L}, e_{T_{L}}\right)$ is represented, respectively.

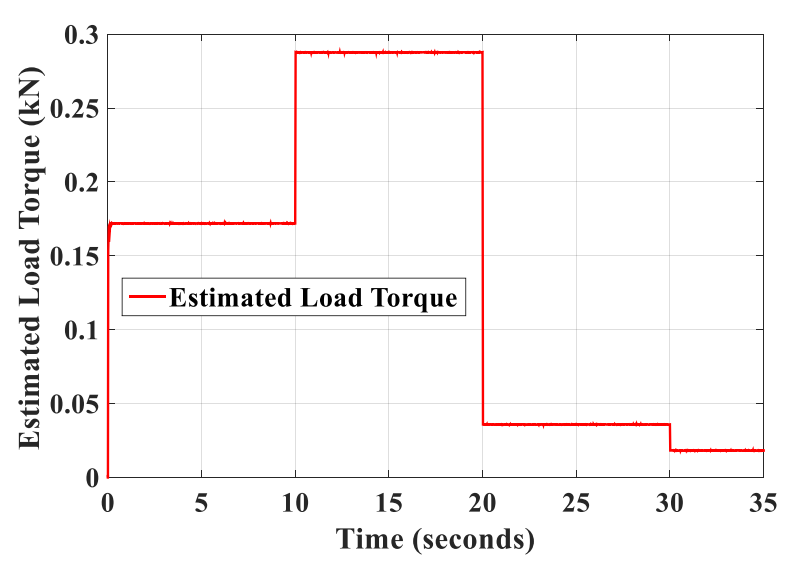

(a)

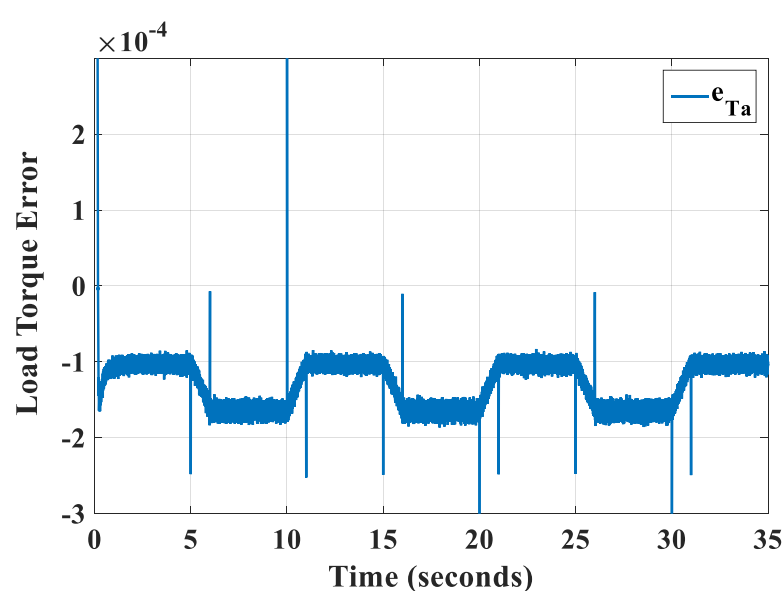

(b)

Figure 6. a) The trajectory of the estimated load torque b) The trajectory of the load torque error.

The trajectory of the estimated motor currents $\left(\hat{I}_{\mathrm{s} \alpha}, \hat{I}_{s \beta}\right)$ and current errors $\left(e_{I_{s \alpha}}, e I_{s \beta}\right)$ are represented in Figure 7 and Figure 8, respectively.

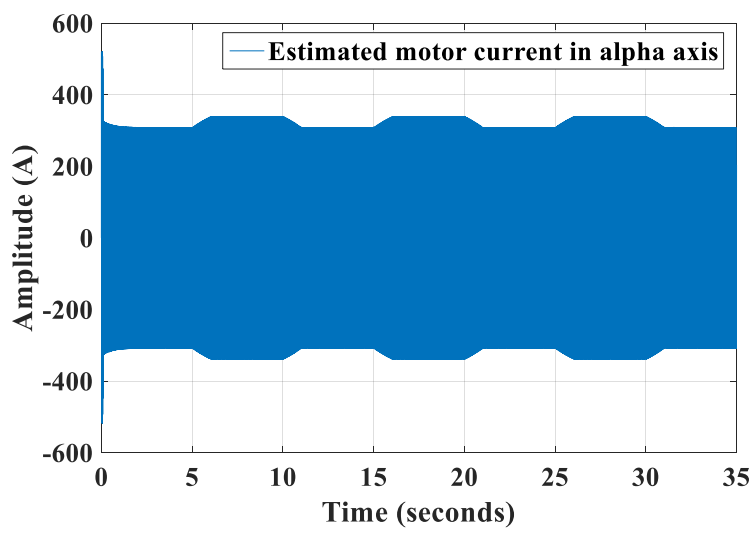

(a)

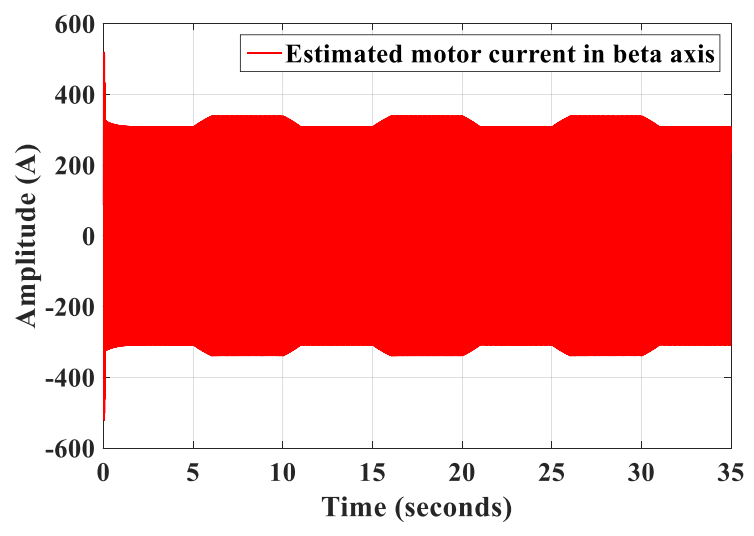

(b)

Figure 7. The trajectories of the estimated motor currents a) in $\alpha$ axis b) in $\beta$ axis. 


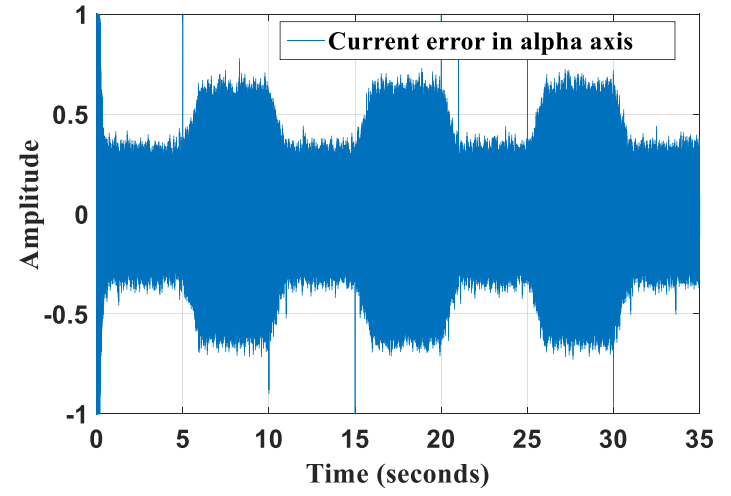

(a)

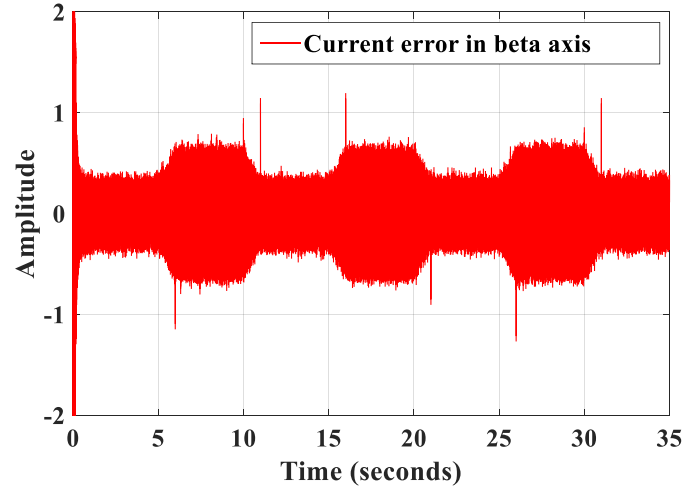

(b)

Figure 8. The trajectories of the motor current errors a) in $\alpha$ axis b) in $\beta$ axis.

The trajectory of the estimated rotor fluxes $\left(\hat{\psi}_{\mathrm{r} \alpha}, \hat{\psi}_{\mathrm{r} \beta}\right)$ and flux errors $\left(e_{\psi_{\mathrm{r} \alpha}}, e I_{\psi_{\mathrm{r} \beta}}\right)$ are represented in Figure 9 and Figure 10, respectively.

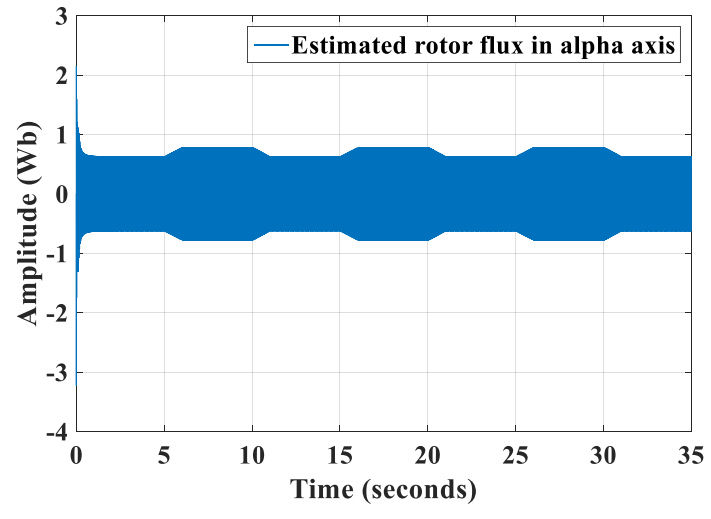

(a)

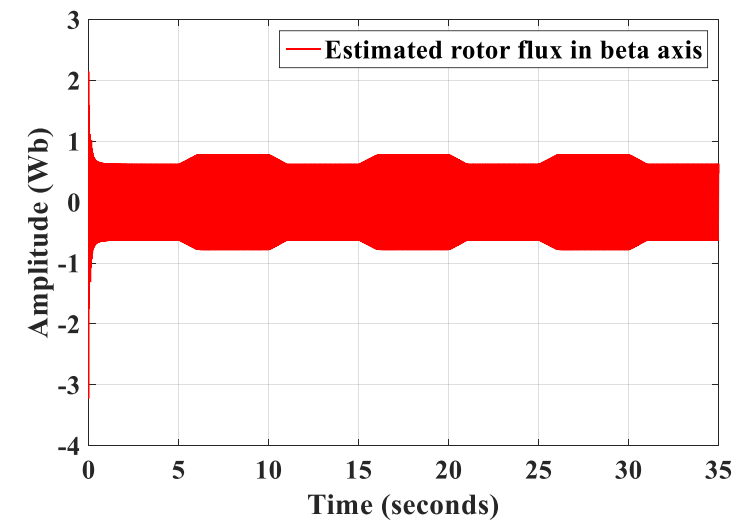

(b)

Figure 9. The trajectories of the estimated rotor fluxes a) in $\alpha$ axis b) in $\beta$ axis.

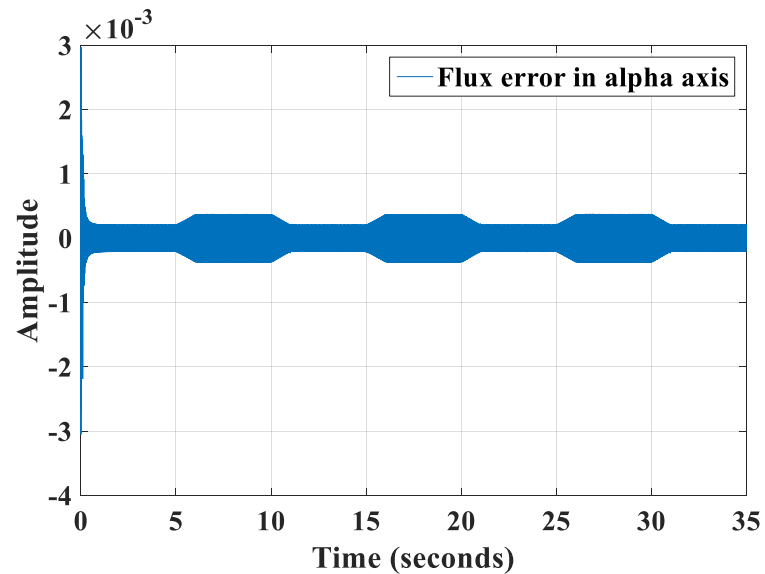

(a)

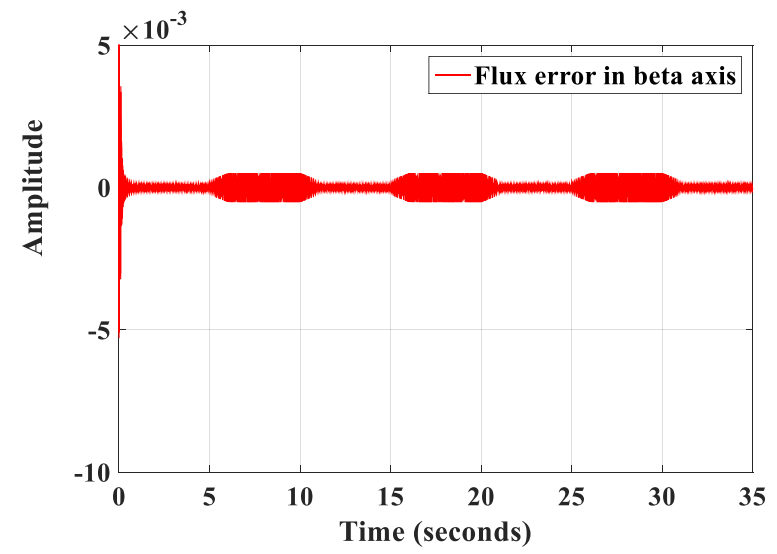

(b)

Figure 10. The trajectories of the motor flux errors a) in $\alpha$ axis b)in $\beta$ axis.

The estimation and actual dynamics of the motor torque $\left(\widehat{T}_{m}, \mathrm{~T}_{m}\right)$ are given in Figure 11 . 


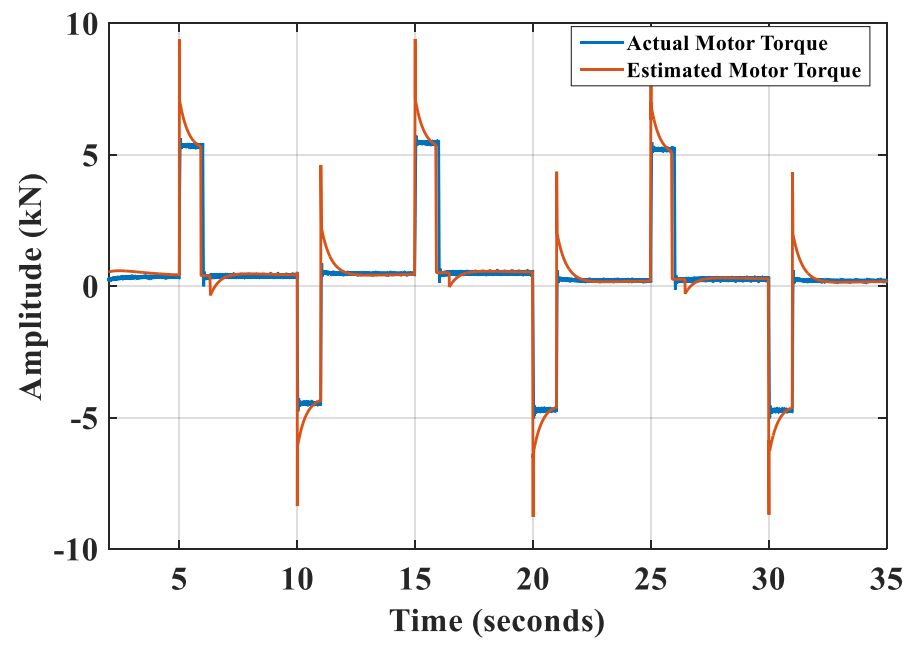

Figure 11. Actual and estimated pattern of the motor torque.

It can be seen that, when the speed command suddenly changes, the error usually changes in a narrow band interval. It can be concluded that the estimator tracks the trajectories of the states with higher precision and converges fast. In Figure 12., the trajectory of the estimated adhesion force $\left(\hat{F}_{a}\right)$ can be derived from the part of the Equation (1) by using estimated load torque data as $\widehat{T}_{L}=\frac{2 r_{0}}{n_{i}} \widehat{F}_{a}$.

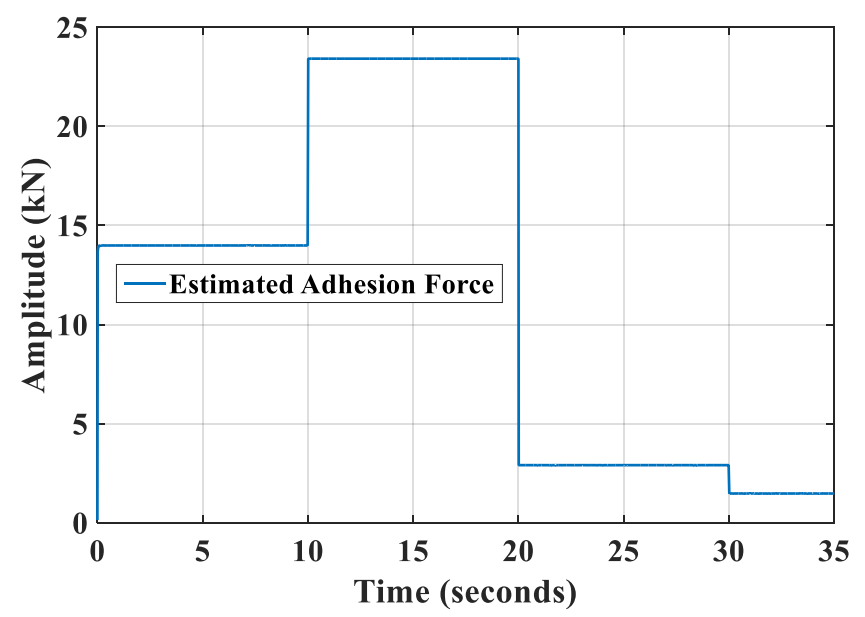

Figure 12. The trajectory of the estimated adhesion force.

With the help of the estimated longitudinal creep force, it is possible to determine the level of the adhesion present, and the effect of the railway vehicle upon the track infrastructure. The performances has been checked into thoroughly at various dynamic operation conditions both simulated and estimated results.

\section{CONCLUSION}

The real-time information about the wheel-rail contact has become essential to satisfy the consistent traction and braking performance. A novel method to detect the wheel-rail contact conditions, which are very hard to be known in practical applications, has been investigated in this paper. An extended Kalman filter (EKF) based condition monitoring is proposed to make it an effective re-adhesion controller. The EKF performance was evaluated by comparing the actual and estimated values of load current, motor speed, stator current and rotor currents. Then the electric motor torque and adhesion force were calculated by moving from the estimated data. It was observed that the EKF responded 
quickly and estimated with low error value, as the adhesion conditions of the wheel-rail contact varied. Different creep curves, which correspond to different contact conditions are utilized in simulations and the estimation results are found robust and accurate. The primary aim of this kind of estimation of these variables is to design a real-time system, which detects local adhesion conditions, and predicts wear generated. With the help of such an estimator, the performance of the re-adhesion controller can be improved, the creepage is reduced, and maximum traction is achieved. It has been proved that proposed EKF estimatior has a superiority in estimation while changing the contact conditions. These predictions can be translated into a useful condition monitoring phase, which seeks to reveal the creep characteristics at low creep values using a scale roller rig, and validation of the techniques generated by a multi-bodied dynamic simulation package such as SIMPACK and data obtained from a full scale railway vehicle. These applications shall be carried out in future works. The lateral dynamics of the vehicle can also be included in the estimator. The estimator performance under varying traction load can also be studied, and several adaptive tuning algorithms should be applied to improve the estimation accuracy and stability with the help of sensors, which perform better resolution, and high sampling rate of the data acquisition system.

\section{REFERENCES}

Alonge, F., D'ippolito, F., 2010, "Extended Kalman Filter for Sensorless Control of Induction Motors", First Symposium on Sensorless Control for Electrical Drives, Padova, Italy, 9-10 July 2010.

Alsofyani, I. M., Idris, N., Sutikno, T., Alamri, Y. A., 2012, “An optimized Extended Kalman Filter for Speed Sensorless Direct Troque Control of An İnduction Motor", IEEE International Conference on Power and Energy, Kota Kinabalu, Malaysia, 2-5 December 2012.

Barut, M., Bogosyan, O., Gokasan, M., 2002, “EKF Based Estimation for Direct Vector Control of Induction Motors", IEEE 28th Annual Conference of the Industrial Electronics Society, Sevilla, Spain, 5-8 November 2002.

Barut, M., Bogosyan, S., Gokasan, M., “EKF Based Sensorless Direct Torque Control of IMs in The Low Speed Range", Proceedings of the IEEE International Symposium on Industrial Electronics, 2005, ISIE 2005, Dubrovnik, Croatia, 20-23 June 2005.

Barut, M., Bogosyan, S., Gokasan, M., 2007, “Speed-Sensorless Estimation for Induction Motors Using Extended Kalman Filters", IEEE Transactions on Industrial Electronics, Vol. 54(1), pp. 272-280.

Barut, M., Gokasan, M., Bogosyan, O., 2003, “An extended Kalman Filter Based Sensorless Direct Vector Control of Induction Motors", IECON'03. 29th Annual Conference of the IEEE Industrial Electronics Society (IEEE Cat. No.03CH37468), Roanoke, VA, USA, 2-6 November 2003.

Bogosyan, S., Barut, M., Gokasan, M., 2007, “Braided Extended Kalman Filters for Sensorless Estimation In İnduction Motors at High-Low/Zero Speed", IET Control Theory E Application, Vol. 1(4), pp. 987-998.

Cai, L., Zhang, Y., Zhang, Z., Liu, C., Lu, Z., 2003, “Application of Genetic Algorithms in EKF for Speed Estimation of an Inducion Motor", Proc. on IEEE Power Electronics Specialist Conference, Acapulco, Mexico, Vol. 1, pp. 345-349, 15-19 June

2003.

Charles, G., Goodall, R., 2006, “Low Adhesion Estimation”, IET International Conference on Railway Condition Monitoring, Birmingham, UK 29-30 Nov. 2006

Gaspar, P., Szabo, Z., Bokor, J., 2006, “Observer Based Estimation of The Wheel-Rail Friction Coefficient", IEEE Conference on Computer Aided Control System Design. Munich, Germany 4-6 Oct. 2006

Hussain, I., Mei, T. X., Ritchings, R. T., 2013, “Estimation of Wheel-Rail Contact Conditions and Adhesion Using The Multiple Model Approach", Vehicle System Dynamics, Vol. 51(1), pp. 32-53. 
Iwnicki, S., 2003, "Simulation of Wheel-Rail Contact Forces", Fatigue Fracture of Engineering Materials and Structures, Vol. 26(10), pp. 887-900.

Kalker, J., 1968, “On The Rolling Contact of Two Elastic Bodies in The Presence of Dry Friction", Wear, Vol. 11(4), pp. 303.

Kawamura, A., Takeuchi, K., Furuya, T., Cao, M., Takaoka, Y., Yoshimoto, K., 2003, "Measurement of Tractive Force and the New Maximum Tractive Force Control by the Newly Developed Tractive Force Measurement Equipment", IEEJ Transactions on Industry Applications, Vol. 123(8), pp. 885-893.

Matsumoto, Y., Eguchi, N., Kawamura, A., 2001, “Novel Re-Adhesion Control for Train Traction System of The "Shinkansen" with The Estimation of Wheel-to-Rail Adhesive Force", IECON'01, 27th Annual Conference of the IEEE Industrial Electronics Society (Cat. No.37243), Denver, CO, USA, Vol. 2, pp. 1207-1212 29 Nov.-2 Dec. 2001

Mei, T., Hussain, I., 2010, "Detection of Wheel-Rail Conditions for Improved Traction Control", IET Conference on Railway Traction Systems, Birmingham, UK 13-15 April 2010

Polach, O., 1999, “A Fast Wheel-Rail Forces Calculation Computer", Veh. Syst. Dyn. Suppl, 1999, Vol. 33, pp. 728-739.

Radionov, I. A., Mushenko, A. S., 2015, "The method of estimation of adhesion at "wheel-railway" contact point", 2015 International Siberian Conference on Control and Communications (SIBCON), Omsk, Russia, 21-23 May 2015.

Rizzo, R., Iannuzzi, D., 2002, "Indirect Friction Force Identification for Application in Traction Electric Drives", Mathematics and Computers in Simulation, Vol. 60(3-5), pp.379-387.

Shi, K., Chan, T., Wong, Y., Ho, S., 2002, Speed Estimation of An İnduction Motor Drive Using an Optimized Extended Kalman Filter", IEEE Transactions on Industrial Electronics, Vol.49(1), pp.124-133.

Singh, K., Singh, M., 2013, "Design of Kalman Filter for Induction Motor Drive" Students Conference on Engineering and Systems (SCES), Allahabad, India, 12-14 April 2013.

Wang, S., Xiao, J., Huang, J., Sheng, H., 2016, “Locomotive Wheel Slip Detection Based on Multi-Rate State İdentification of Motor Load Torque", Journal of the Franklin Institute, 2016, Vol. 353(2), pp. 521-540.

Ward, C. P., Goodall, R. M., Dixon, R., 2011, "Contact Force Estimation in the Railway Vehicle WheelRail Interface", IFAC Proceedings Volumes, Vol. 44(1), pp. 4398-4403.

Ward, C., Goodall, R., Dixon, R., Charles, G., 2012, “Detection of Low Adhesion in The Railway Vehicle Wheel/Rail İnterface: Assessment of Multi-Bodied Simulation Data, Proceedings of 2012 UKACC International Conference on Control, Cardiff, UK, 3-5 September 2012.

Zhao, Y., Liang, B., 2013, "Re-adhesion Control for A Railway Single Wheelset Test Rig Based on The Behaviour of The Traction Motor", Vehicle System Dynamics, Vol. 51(8), pp. 1173-1185.

Zhao, Y., Liang, B., Iwnicki, S., 2012, "Estimation of the Friction Coefficient Between Wheel and Rail Surface Using Traction Motor Behaviour", Journal of Physics: Conference Series, 2012, Vol. 364, 012004.

Zhao, Y., Liang, B., Iwnicki, S., 2014, "Friction Coefficient Estimation Using an Unscented Kalman Filter", Vehicle System Dynamics, Vol. 52(Sup1), pp. 220-234. 